\title{
Muz yalancı gövde atığının kağıt hamuru ve kağıt üretimine uygunluğunun kimyasal ve morfolojik açıdan değerlendirilmesi
}

\author{
Evren Ersoy Kalyoncu a,* (iD, Meryem Ondarala ${ }^{a}$
}

\begin{abstract}
Özet: Bu çalışmada dünyada yaygın bir tarım alanına sahip muz bitkisinin (Musa sapientum) meyve hasadı sırasında oldukça fazla miktarda oluşan gövde atıklarının, kağıt endüstrisinde hammadde olarak kullanılabilirliğinin kimyasal ve morfolojik açıdan uygunluğunun araştırılması amaçlanmıştır. Muz yalancı gövdesinin başlıca kimyasal bileşenleri holoselüloz, $\alpha$-selüloz ve lignin sirasıyla $\% 77.5, \% 51.0$ ve \%12.7 olarak tespit edilmiștir. Sıcak su çözünürlüğü \%17.3, soğuk su çözünürlüğü \%13.0, alkol ve \%1 $\mathrm{NaOH}$ çözünürlük değerleri ise sırasıyla \%9.2 ve \%33.3 olarak bulunmuştur. Lif uzunluğu bakımından iğne yapraklı ağaç odunu liflerine, lif genişliği bakımından ise yapraklı ağaç odunu liflerine benzeyen muz yalancı gövde atığı liflerinin düşük Runkel oranı, rijitlik katsayısı ve Mühlstep oranı ile yüksek narinlik ve esneklik oranlarına sahip olduğu tespit edilmiştir. Kimyasal ve morfolojik analizlerden elde edilen sonuçlar, muz yalancı gövde atıklarının kağıt hamuru ve kağıt üretimi için uygun bir hammadde olduğunu göstermiştir.

Anahtar kelimeler: Muz yalancı gövde, Kimyasal özellikler, Morfolojik özellikler, Kağıt hamuru ve kağıt üretimi, Tarımsal atık
\end{abstract}

\section{Chemical and morphological evaluation of the suitability of banana pseudo-stem waste for pulp and paper production}

\begin{abstract}
In this study, it was aimed to investigate the chemical and morphological suitability of using pseudo-stem which are formed in large amounts during the fruit harvesting of the banana plant (Musa sapientum) with a widespread agricultural area in the world, as raw material in the paper industry. The main chemical constituents of banana pseudo-stem holocellulose, $\alpha$ cellulose and lignin were determined as $\% 77.5, \% 51.0$ and $\% 12.7$, respectively. Hot water solubility was $17.3 \%$, cold water solubility $13.0 \%$, alcohol and $1 \% \mathrm{NaOH}$ solubility values were $9.2 \%$ and $33.3 \%$, respectively. It has been determined that banana pseudo-stem waste fibers, which are similar to softwood fibers in terms of fiber length and hardwood fibers in terms of fiber width, have high slenderness and flexibility ratios with low Runkel ratio, rigidity coefficient and Mühlstep ratio. The results obtained from chemical and morphological analyzes indicated that banana pseudo stem waste is a suitable raw material for pulp and paper production.

Keywords: Banana pseudo-stem, Chemical properties, Morphological properties, Pulp and paper production, Agricultural waste
\end{abstract}

\section{Giriș}

Her geçen gün artan dünya nüfusuna bağlı olarak ihtiyaçlar doğrultusunda tüketim malzeme gereksinimleri artmakta, yaşam kolaylaştırıcı ürünler giderek yaygınlaşmakta ve tüm bunlarla orantılı olacak şekilde çevre kirliliği de artmaktadır. Küresel nüfus artışının bir sonucu olarak artan besin ihtiyacı ile üretilen tarımsal ürünlerin büyük miktarlarda işlenmemiş atıkları da oluşmaktadır. Tarımsal ürünlerin hasadı sırasında oluşan atıkların önemli bir kısmı ortamda birakılarak ya da yakılarak uygun bir şekilde değerlendirilememektedir. Tarımsal atıkların bertaraf edilmesi sırasında doğal çevre üzerinde önemli olumsuz etkiler oluştuğu gözlenmektedir (Kara ve Sezer, 1992). Tarımsal atıkların faydaya dönüştürülmesi üzerine yapılan çalışmaların giderek yaygınlaşması nedeniyle yeni teknolojiler geliştirilmiş ve bu sayede tarımsal atıklardan olabildiğince fazla değer elde edilebilmek amaçlanmıştır.
Özellikle, meyve bahçelerinde, hasat ve bakım işlemleri sırasında önemli miktarlarda atık meydana gelmektedir.

En yaygın tüketim malzemelerinden olan kağıt-karton üretimi için yeterli hammadde kaynağının bulunmaması, çeşitli çevresel ve ekonomik kaygılar nedeniyle alternatif hammadde arayışlarını gündeme getirmiştir (Tutuş ve Çiçekler, 2016). Kağıt endüstrisinde selülozik lif kaynağı olarak odun dışı hammaddelerin yanında tarımsal atıkların da kullanılması giderek önem kazanmaktadır. Kivi budama artıklarının lif morfoloik özellikleri bakımından kağıt hamuru üretimine uygunluğu (Yaman ve Gençer, 2015) ve bu atıklardan kraft yöntemi ile üretilen kağıtların yapraklı ağaç odunundan elde edilen kağıtlar ile rekabet edecek sevide olduğu (Gençer, 2015) belirtilmiştir.

Neredeyse tüm dünyada yetişen ve her yıl yaklaşık 120150 milyon ton yetiștirilen muz (Musa spp.) dünyada dördüncü en önemli gıda ürünüdür (Reddy ve Yang, 2015). Önemli gıda ürünü olması nedeniyle, 150 ülkede 4.84 hektarlık bir alanda 95.6 milyar ton üretilmektedir (Singh

\footnotetext{
$\triangle$ a Karadeniz Teknik Üniversitesi, Arsin Meslek Yüksekokulu, Malzeme ve Malzeme İşlem Teknolojileri Bölümü, 61900, Arsin/Trabzon

@ * Corresponding author (İletişim yazarı): eersoy@ktu.edu.tr

$\checkmark \quad$ Received (Geliş tarihi): 12.04.2021, Accepted (Kabul tarihi): 14.06.2021
}

Citation (Atıf): Ersoy Kalyoncu, E., Ondaral, M., 2021. Muz yalancı gövde atığının kağıt hamuru ve kağıt üretimine uygunluğunun kimyasal ve morfolojik açıdan değerlendirilmesi. Turkish Journal of Forestry, 22(2): 143-150. DOI: $\underline{10.18182 / \text { tjf. } 913696}$ 
vd., 2011). Ülkemizde 2020 y1lı istatistiklerine göre 111.544 dekar alanda toplam 728 bin ton muz üretimi gerçekleştirilmiştir (TUIK, 2021). Gerçek ve yalancı gövde olmak üzere iki kısımdan oluşan muz bitkisinin yalancı gövde kısmı meyve hasadının ardından kesilerek atılmaktadır (Khan vd., 2014; Ortega vd., 2016). Her yıl muz ekim alanlarında önemli miktarlarda atık ürünler oluşmaktadır (Padam, 2014). Muz üretim seralarında her hafta yapılan yalancı gövde kesimi nedeniyle üretim sırasında ortaya çıkan atık, ülkemiz için de ciddi bir potansiyel oluşturmaktadır. Demirel ve Pınar (2019), 2018 yılı için üretimi yapılan 498.888 ton muz için tarımsal faaliyetler sonucunda yaklaşık olarak 209.448 ton kuru biyokütle artığı açığa çıktığı belirtilmiştir. Genellikle yakılarak imha edilen veya hiç işlem yapılmadan çöpe atılan bitkinin bu atık kısmı yüksek selüloz yüzdesine ve nispeten iyi mekanik özelliklere sahip olarak kağıt-karton üretiminde hammadde olarak avantajlı özelliklere sahiptir ve umut vaat etmektedir (Poonam ve Gupta, 1991; Pothan vd., 2010; Kumar ve Kumar, 2011; Singh ve Bandyopadhyay, 2013; Khan vd., 2014; Ramesh vd., 2014). Bir dönümlük arazi de ortalama 1000 ila 1500 adet oluşan yalancı gövde atıklarının 10-13'ü ile 1-2 kg muz lifi üretilebilir (Hussain ve Tarar, 2014). Bulunabilirliğinin kolay olması, sürekliliği, düşük maliyeti ve yüksek mekanik özellikleri doğal liflere özgü avantajlı özelliklerdir (Khan vd., 2014). Bu açıdan muz bitkisinin yalancı gövde atıklarının kağıt endüstrisinde hammadde olarak değerlendirilmesi önemli bir öneridir. Oldukça fazla oranda oluşan hasat atıkları, artan çevresel kaygılar, mevsimsel üretilebilirlik ve düşük üretim maliyetleri muz yalancı gövdesi atık liflerinin kağıt yapımında kullanımının mantıklı olduğunu göstermektedir (Soffner, 2001).

Çevresel faktörler göz önünde bulundurulursa lignoselülozik yapı gösteren atıl ve atık muz yalancı gövdelerinin hammadde olarak kullanımının uygunluğu bu çalışmada araştırılmıştır. Bu amaçla kimyasal ve lif morfolojik özellikleri belirlenerek lif boyutlarının birbirlerine oranlanması ile bulunan indeks değerleri (keçeleşme oranı, elastiklik katsayısı, rijidite katsayısı, runkel oranı, Mühlstep oranı ve F oranı) hesaplanmıştır. Elde edilen sonuçlar çeşitli lignoselülozik malzemelerin özellikleriyle mukayese edilmiş ve kâğıtçılığa uygunluğu araştırılmıştır.

\section{Materyal ve yöntem}

\subsection{Materyal}

Çalışmada, Mersin-Türkiye'de bir muz plantasyon alanından tedarik edilen muz bitkisinin meyve hasadı sırasında atık olarak ortaya çıkan muz yalancı gövde atıkları hammadde olarak kullanılmıştır. Kir, kum ve safsızlıklarından arındırmak için musluk suyu ile yıkanarak temizlenmiş ve yaklaşık 1 hafta boyunca açık havada kurutulmuştur.

\subsection{Yöntem}

Bu çalışma, Karadeniz Teknik Üniversitesi (KTÜ), Orman Fakültesi, Orman Ürünleri Kimyas1 Laboratuvarı'nda gerçekleştirilmiştir.

\subsubsection{Kimyasal analizler}

Muz yalancı gövdenin kimyasal özelliklerini belirlemek üzere hava kurusu hale getirilen örneklerinin kimyasal analizlerde kullanılacak yeterli miktarı TAPPI T 257 sp-14 (2014) standart yöntemine uygun olacak şekilde hazırlanmıştır. $\mathrm{Bu}$ amaçla hava kurusu örnekler öncelikle kesici bir aletle Şekil 1'deki gibi 3-4 cm uzunluğunda kesilmiştir. Standarda uygun olacak şekilde laboratuar tipi Wiley değirmeninde öğütülen örnekler ardından sarsıntılı eleklerde elenmiş, 40 mesh elekten geçip 60 mesh elek üzerinde kalan kısımlar alınmıştır. Rutubetleri belirlenen örnekler kimyasal analizlerde kullanılmak üzere hava almayacak şekilde saklanmıştır.

Örneklere aşağıdaki kimyasal analizler uygulanmıştır:

- Holoselüloz tayini: Wise Klorit metodu (Wise ve Karl, 1962)

- $\alpha$-selüloz tayini: TAPPI T 203 cm-09 (TAPPI, 2009)

- Lignin tayini: TAPPI T 222 om-15 (TAPPI, 2015)

- Kül tayini: TAPPI T 211 om-16 (TAPPI, 2016)

- Silis tayini: TAPPI T 245 cm-07 (TAPPI, 2007)

- Soğuk su çözünürlüğü TAPPI T 207 om-08 (TAPPI, 2008)

- Sicak su çözünürlüğü TAPPI T 207 om-08 (TAPPI, 2008)

• \%1'lik NaOH çözünürlügü TAPPI T 212 om-12 (TAPPI, 2012)

• Etanol çözünürlüğü TAPPI T 204 cm-17 (TAPPI, 2017)

Her analiz üç tekrar olacak şekilde gerçekleştirilmiş ve ortalama değerler alınarak tam kuru ağırlığa göre rapor edilmiştir.

\subsubsection{Morfolojik özellikler}

Liflerin morfolojik ölçümlerinin yapılması amacıyla yıkanıp kurutulan muz yalancı gövde atıkları 3-5 cm boyutlarına getirilerek Franklin metoduna (Franklin, 1945) uygun olacak şekilde maserasyon işlemine uğratılmıştır. Bu yönteme göre alınan örnekler, ağzı kapaklı cam erlende \% 98 asetik asit ve \% 30 hidrojen peroksitten eşit hacimde (1:1) alınarak hazırlanan karışım ile $60{ }^{\circ} \mathrm{C}$ 'de 48 saat süreyle işleme tabi tutularak lifler bireysel hale getirilmiştir. Elde edilen liflerden rastgele örnek alınarak kalıcı preparatlar hazırlanmıştır. Ölçümler için Projectina 1 şık mikroskobu kullanılmıştır. Lif uzunluğu ölçümü için 56x, lif çapı ve lümen genişliği ölçümü için 90x büyütme yapılmıştır. Mikroskop altında incelenen preparatlardan çekilen dijital fotoğraflar Şekil 2'de görülmektedir.

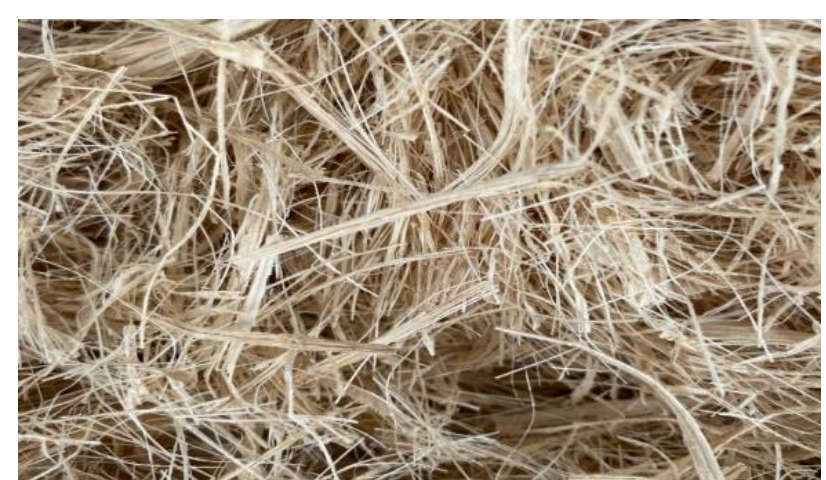

Şekil 1. Muz yalancı gövde atığı 


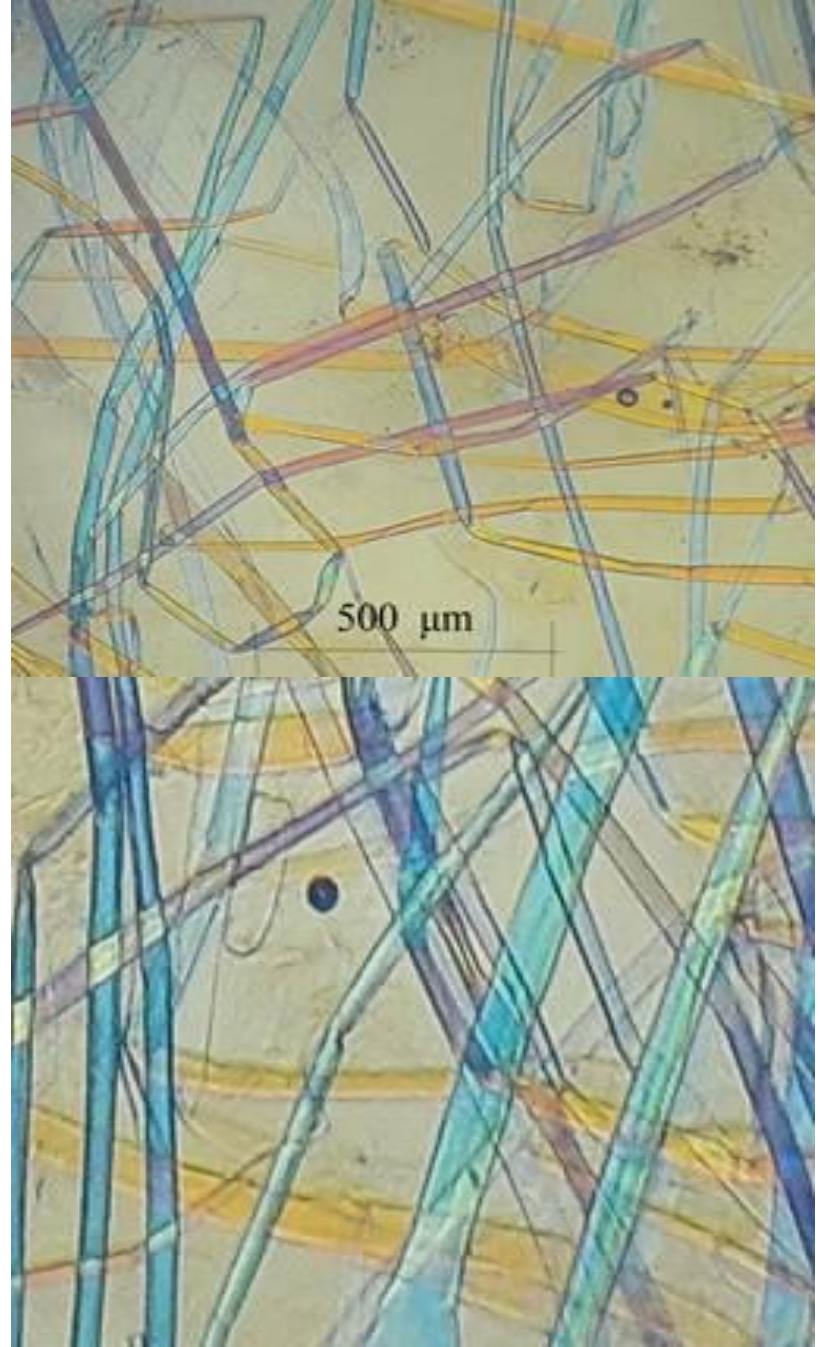

Şekil 2. Maserasyon işlemine tabii tutulmuş muz yalancı gövde atıklarının mikroskobik görüntüleri
Çekilen dijital fotoğraflar, DIGIMER ${ }^{\mathrm{TM}}$ görüntü analiz programı ile her bir lif boyutu analiz edilerek belirlenmiştir. Her bir lif boyutu için, her slayttan rastgele 100 lif ölçümü yapılmıştır. Ölçüm sonucu elde edilen verilerden ortalama lif boyutları tespit edildikten sonra Elastiklik Oranı (Petri, 1952), Runkel Sinıflandırması (Okere, 1962), Keçeleşme Oranı (Rydholm, 1965; Kırc1, 2000) ve Katılık Katsayıs1 (Eroğlu, 2003) aşağıda belirtilen formüller ile hesaplanmıştır.

Keçeleşme orani = Lif Uzunluğu / Lif Genişliği

Elastiklik katsayısı $(\%)=($ Lümen Çapı / Lif Genişliği $)$ x 100

Rijidite katsayısı $=($ Lif Çeper Kalınlığ $1 /$ Lif Genişliği $) \times 100$

Runkel oranı= 2 x (Lif çeper Kalınlığ $/$ Lümen Çapı)

Mühlstep oranı $(\%)=($ Hücre Çeper Alanı / Lif Enine Kesit Alanı) $x$ 100

F Oranı $(\%)=($ Lif Uzunluğu/ Lif Çeper Kalınlığ 1$) \times 100$

\section{Bulgular ve tartışma}

Muz yalancı gövde atık örneklerine ait kimyasal içerik ve çözünürlüklerine ait veriler çeşitli bitkisel saplar, yapraklı ve iğne yapraklı ağaçların referans değerleri ile karşılaştırmalı olarak Çizelge 1'de verilmiştir. Holoselüloz, lignin ve ekstraktif maddeler odun ve odun dışı lignoselülozik ürünlerin ana bileşenlerini oluşturmaktadır. Çizelge 1 incelendiğinde, muz yalancı gövde atığının holoselüloz içeriğinin $(\% 77.5)$ çizelgedeki diğer tarımsal lignoselülozik referansların çoğundan daha yüksek olduğu ve yapraklı ağaç (YA) odununa daha yakın değer verdiği tespit edilmiştir. Holoselüloz içeriği selüloz, hemiselüloz ve çeşitli lifsel kalıntılardan oluşmaktadır. Hammaddedeki yüksek holoselüloz içeriği, yüksek kağıt mukavemeti özellikleri ile ilişkilidir (Shakhes vd., 2011). Yüksek holoselüloz içeriğine sahip hammaddelerden üretilen kağıt hamurlarının verimleri de yüksek olmaktadır (Ashori vd., 2011).

Çizelge 1. Muz yalancı gövde atığı ve kağıt yapımında yaygın kullanılan bazı lignoselülozik liflerin kimyasal bileşimleri ve çözünürlükleri (Tam kuru örneğe oranla)

\begin{tabular}{|c|c|c|c|c|c|c|c|c|c|c|}
\hline \multicolumn{6}{|c|}{ Kimyasal Bileşen (\%) } & \multicolumn{4}{|c|}{ Çözünürlük (\%) } & \multirow[b]{2}{*}{ Referans } \\
\hline Türler & Holoselüloz & $\alpha$-Selüloz & Lignin & $\begin{array}{c}\text { Toplam } \\
\text { kül }\end{array}$ & Silis & Etanol & $\begin{array}{c}1 \% \\
\mathrm{NaOH}\end{array}$ & $\begin{array}{c}\text { Sicak } \\
\text { su }\end{array}$ & $\begin{array}{c}\text { Soğuk } \\
\text { su }\end{array}$ & \\
\hline $\begin{array}{l}\text { Muz yalanc1 } \\
\text { gövde atığ1 }\end{array}$ & 77.5 & 51.0 & 12.7 & 5.3 & 0.98 & 9.2 & 33.3 & 17.3 & 13.0 & Tespit \\
\hline Buğday sap1 & 75.9 & 47.7 & 20.1 & 6.2 & 4.42 & $7.8^{*}$ & 44.3 & 10.0 & 8.6 & Kalyoncu, 2011 \\
\hline Bagas & 70.6 & 42.0 & 20.3 & 3.8 & 2.10 & $6.3^{*}$ & 33.6 & 7.8 & 5.9 & Dutt, 1994 \\
\hline Bambu & 70.5 & 43.3 & 24.5 & 1.3 & - & $3.9^{*}$ & 25.1 & 6.47 & - & Deniz ve Ateş, 2002 \\
\hline Çavdar sapı & 74.1 & 44.4 & 15.1 & 3.2 & - & $9.2 *$ & 39.2 & 13.0 & 10.2 & Usta ve Eroğlu, 1987 \\
\hline M1sır sap1 & 67.5 & 44.5 & 20.2 & 8.10 & - & $13.0^{*}$ & 44.7 & 18.1 & 17.4 & Akgül vd.,2010 \\
\hline Pirinç sapı & 71.9 & - & 25.2 & 13.6 & 12.18 & $4.8 *$ & 49.8 & 15.2 & 4.8 & Goyal ve Ray, 1989 \\
\hline Göl Kamışı & 77.9 & 47.5 & 18.7 & 3.9 & & $4.0^{*}$ & 28.3 & 3.8 & 3.3 & Kirci, 1996 \\
\hline Kenaf & 81.2 & 37.4 & 14.5 & 4.1 & - & 5.0 & 34.9 & 12.8 & 11.7 & Atchison ,1993 \\
\hline Kenevir & 86.7 & 63.7 & 6.5 & - & - & $4.2^{*}$ & 29.5 & 9.0 & 7.7 & Gumuskaya ve Usta, 2006 \\
\hline Pamuk sapı & 72.2 & 41.6 & 19.3 & 2.4 & - & $6.1 *$ & 42.9 & 17.8 & 16.7 & Akgül ve Tozluoğlu, 2009 \\
\hline Tütün sap1 & 67.6 & 37.5 & 19.5 & 7.3 & - & 6.5 & 42.9 & 19.1 & 15.8 & Tank vd.,1985 \\
\hline Ayçiçek sapı & 74.9 & 37.5 & 18.2 & 8.2 & - & $7.0^{*}$ & 29.8 & 16.5 & 15.5 & Eroğlu vd.,1992 \\
\hline IYYA & $63-74$ & - & $25-32$ & $0.2-0.5$ & - & $1-5.8^{*}$ & $8-10$ & $1-5$ & $0.5-4$ & Kirc1, 2006 \\
\hline YA & $72-82$ & - & $18-26$ & $0.2-0.7$ & - & $1-6.2^{*}$ & $12-25$ & $1-8$ & $0.2-4$ & Kirc1, 2006 \\
\hline
\end{tabular}

*Alkol-benzen, IYYA: İğne Yapraklı Ağaç, YA. Yapraklı Ağaç 
Kağıt hamuru üretimi için hammadde seçiminde $\alpha$ selüloz, oldukça önemli bir ana faktördür (Rahman vd., 2014). Kağıt sektöründe holoselüloz ve $\alpha$ - selüloz miktarlarının yüksek olması istenmektedir (Ashori vd., 2011). Nieschlag ve arkadaşlarının (1960) yaptıkları çalışmaya göre, $\alpha$-selüloz içeriği \% 34 veya daha fazla olan odun dişı yıllık bitkilerin kağıt hamuru ve kağıt üretiminde hammadde olarak kullanımının umut verici olarak düşünülmektedir (Nieschlag vd., 1960; Ververis vd., 2004). Çizelge 1'de görüldüğü gibi muz yalancı gövde atığının $\alpha$ selüloz içeriğinin \%51.0 oranı ile diğer tüm örneklerden daha yüksek değere sahiptir. Bu nedenle yüksek holoselüloz ve $\alpha$ - selüloz oranlarına sahip muz yalancı gövde atığının kağıt hamuru ve kağıt üretimi için tercih edilebilir ve gelecek vaat eden bir hammadde olacağını göstermektedir.

Hammaddenin lignin oranının düşük veya yüksek olması pişirme koşullarının belirlenmesinde bir göstergedir (Eroğlu, 1980). Çizelge 1'e göre muz yalancı gövde atığının lignin içeriği \%12.7 oranı ile kenevir hariç diğer tüm bitkisel sap örnekleri ile yapraklı ağaç ve iğne yapraklı ağaç lignin içeriklerinden oldukça düşüktür. Düşük lignin içeriği hammaddeyi kağıt hamuru üretimi için değerli kılan bir özelliktir. Muz bitkisi, Musaceae familyasından Musa cinsine aittir (Nicemol, vd., 2007; Ortega vd., 2016) ve daha önce yapılan çalışmalarda Musa türlerinin selüloz açısından oldukça zengin olduğu, ve yapraklı ağaç odunlarına kıyasla düşük lignin içeriğine sahip olduğu tespit edilmiştir (Omotoso ve Ogunsile, 2009). Düşük lignin içeriği kolay delignifikasyon, kısa süreli hamurlaştırma işlemi, düşük kimyasal tüketimi ve düşük enerji gereksiniminin göstergesidir (Omotoso ve Ogunsile, 2009). Muz yalancı gövde atığı, yüksek holoselüloz içeriğine ve düşük lignin içeriğine sahip olması nedeniyle kağıt hamuru üretimi ve kağıt yapımı için ideal bir hammaddedir ve hammadde olarak diğerlerine göre daha avantajlıdır (Li vd., 2010). Odun olmayan hammaddelerin en önemli özelliği odunsu türlere göre yüksek kül ve silis içeriğine sahip olmasıdır (Hurter, 1997; Tutus vd., 2010). Kâğıt sektöründe hammadde ekstraktif madde miktarının yüksek olması istenmeyen bir durumdur. Yüksek kül içeriği, kâğıt hamuru üretiminde alkali tüketimini olumsuz etkilemekte, siyah çözeltinin geri kazanılmasında problem oluşturmakta kağıt hamuru üretimini zorlaştırmaktadır (Ilvessalo-Pfäffli, 1995; Omotoso ve Ogunsile, 2009; Ashori vd., 2011). Birçok kaynakta muz hammaddesinin yüksek kül içeriğinden bahsedilmesine rağmen yapılan bu çalışmada muz yalancı gövde atığının kül içeriği \%5.3 olarak tespit edilmiştir. Bu değer birçok yıllık bitki sapları ile benzer olup IYA ve YA odunların kül içeriklerinden daha yüksektir. Ancak silis içeriğinin \%0.98 değeri ile Çizelge 1'deki diğer hammaddelerin silis içeriklerinden oldukça düşük oranda olduğu tespit edilmiştir.

Yüksek ekstraktif madde içeriğine sahip hammaddeler üretilen kağıt hamurunun rengini ve parlaklığını olumsuz yönde etkilemekte ve ağartma masraflarını arttırmaktadır (Bozkurt ve Erdin, 1989). Yüksek ekstraktif içeriği odun hammaddelerine kıyasla daha düşük hamur verimi ile sonuçlanabilir (Omotosa ve Ogunsile, 2009). Etanol, aseton veya diklorometan gibi organik çözücülerle ekstrakte edilen maddeler lipofilik ekstraktifler olarak ifade edilir (Sun ve Tomkinson, 2003). Etanolde çözünen ekstraktların miktarı bozunma direnci ile ilişkilidir (Wilcox ve Piirto, 1976). Bu çalışmada, ekstraktların çözünürlüğünü belirlemek için aynı standarda (TAPPI T $204 \mathrm{~cm}-07)$ bağlı olarak alkol-benzen yerine etanol kullanılmış ve \%9.2 etanol çözünürlüğü elde edilmiştir. Daha önce yapılan çalışmalarda Musa türlerinin yüksek etanol-benzen çözünürlüğüne sahip olduğu belirtilmiştir (Sharma vd., 2011; Oluwasina ve Lajide, 2016).

$\% 1 \mathrm{NaOH}$ çözünürlüğü, hemiselüloz ve degrade olmuş selülozdan oluşan düşük molekül ağırlıklı karbonhidrat miktarını göstermekte (Sharma vd., 2011; Oluwasina ve Lajide, 2016) ve çürüme ile ilişkilendirilmektedir. Bu nedenle kağıt hamuru ve kağıt üretiminde kullanılacak hammaddenin \%1 NaOH çözünürlük oranın düşük olması arzu edilmektedir (Khristova, 1998). Çizelge 1'den de görüldügü üzere, muz yalancı gövde atığının \%33.3 oranındaki \% $1 \mathrm{NaOH}$ çözünürlüğü, iğne yapraklı ağaç (IYA) ve yapraklı ağaç (YA) odun değerlerine kıyasla daha yüksek değerde olmasına rağmen çizelgedeki diğer lignoselülozik yıllık bitki sapları ile benzer oranda olmuştur. Muz yalancı gövde atığının sicak su ve soğuk su çözünürlükleri sırasıyla \%17.3 ve \%13.0 oranlarında tespit edilmiştir. $\mathrm{Bu}$ değerler hem iğne yapraklı (IYA) hem de yapraklı ağaç (YA) odun değerlerinden hem de çizelgede verilen birçok lignoselülozik malzemelerden yüksek bulunmuştur. $\mathrm{Bu}$ durum, muz yalancı gövde atığında tanenler, sakızlar, şekerler ve renklendirici maddeler gibi yüksek inorganik bileşiklerin varlığına bağlanmaktadır (Redondo-Gómez vd., 2020).

Morfolojik analiz sonucu elde edilen lif boyutları ve morfolojik özelliklerden türetilen indeks değerleri sırasıyla Çizelge 2 ve Çizelge 3 'de gösterilmiştir. Karşılaştırma yapabilmek amacıyla çizelgede bazı lignoselülozik hammadde olarak yıllık bitki saplarına da yer verilmiştir.

Liflerin morfolojik özelliklerinin kağıt özellikleri üzerinde önemli oranda olumlu etkisi bulunmaktadır (Bozkurt ve Erdin, 1989). Çizelge 2 incelendiğinde muz yalancı gövde lif uzunluğunun $2.7 \mathrm{~mm}$ ve lif genişliğinin de $22.84 \mu \mathrm{m}$ olduğu görülmektedir. Bu değerler abaka hariç Çizelge 2'deki neredeyse tüm yıllık bitki sapları ile aynıdır. Muz bitkisi (Musa sapientum) ve abaka aynı türden olup birbirlerine yapısal olarak oldukça benzerdir (Bande vd., 2013). Muz yalancı gövde atığı ve abaka liflerini diğer odun dışı hammaddelerden ayıran en önemli özellik, hücre çeper kalınlıklarının diğer türlerden daha ince olmasıdır. Muz yalancı gövde atığı lifi $2.93 \mu \mathrm{m}$ değeri ile abaka lifine göre $(1.8 \mu \mathrm{m})$ daha kalın hücre çeperine sahiptir. IYYA ve YA odun lifleri ile karşılaştırıldığında muz yalancı gövde atığı lifleri uzunluk bakımından IYA liflerine, lif genişliği bakımından ise YA odunu liflerine benzemektedir. 
Çizelge 2. Muz yalancı gövde atığı ve kağıt yapımında yaygın kullanılan bazı lignoselülozik liflerin morfolojik özellikleri

\begin{tabular}{|c|c|c|c|c|c|}
\hline Türler & $\mathrm{L}$ & $\mathrm{D}$ & $\mathrm{d}$ & $\mathrm{W}$ & Referans \\
\hline Muz yalancı gövde atığ1 & 2.7 & 22.84 & 16.98 & 2.93 & Tespit \\
\hline Buğday sap1 & 0.74 & 13.20 & 4.02 & 4.59 & Deniz v, 2004 \\
\hline Pirinç sap1 & 0.89 & 14.80 & 6.40 & 4.20 & Tutuş vd., 2004 \\
\hline Çavdar sapı & 1.15 & 14.7 & 4.2 & 5.25 & Usta ve Eroğlu, 1987 \\
\hline Misır sap1 & 1.32 & 24.3 & 10.7 & 6.8 & Usta vd., 1990 \\
\hline Pamuk sapı & 0.81 & 24.98 & 16.75 & 4.12 & Tutuş vd., 2010 \\
\hline Kenaf (tüm gövde) & 1.29 & 22.1 & 12.7 & 4.3 & Ververis vd.,2004 \\
\hline Göl Kamışı & 1.39 & 13.5 & 7.0 & 3.25 & Kırc1, 1996 \\
\hline Bagas & 1.59 & 21.0 & 9.7 & 5.65 & Mather ve Wardman, 2010 \\
\hline Abaka & 3.35 & 23.2 & 19.6 & 1.8 & Moreno vd.,2005 \\
\hline Bambu & 2.30 & 15.1 & 6.9 & 4.10 & Deniz ve Ateş, 2002 \\
\hline Kivi & 1.58 & 35.97 & 22.30 & 6.84 & Yaman ve Gençer, 2005 \\
\hline İYA & $2-7$ & $32-43$ & - & - & Atchison, 1987 \\
\hline YA & $0.7-1.6$ & $20-40$ & - & - & Atchison, 1987 \\
\hline
\end{tabular}

Çizelge 3. Muz yalancı gövde atığı ve kağıt yapımında yaygın kullanılan bazı lignoselülozik liflerin morfolojik özelliklerinden türetilmiş indeks değerleri

\begin{tabular}{|c|c|c|c|c|c|c|c|}
\hline Türler & $\begin{array}{c}\text { Keçeleşme } \\
\text { oran1 } \\
\text { (L/D) }\end{array}$ & $\begin{array}{c}\text { Elastiklik } \\
\text { katsayısı }(\%) \\
(\mathrm{d} / \mathrm{D}) .100\end{array}$ & $\begin{array}{c}\text { Rijidite } \\
\text { katsay1s1 (\%) } \\
\text { (W/D).100 }\end{array}$ & $\begin{array}{c}\text { Runkel oranı } \\
2 \mathrm{~W} / \mathrm{d}\end{array}$ & $\begin{array}{c}\text { Mühlstep oran1 } \\
(\%) \\
100 .\left(\mathrm{D}^{2}-\mathrm{d}^{2}\right) / \mathrm{D}^{2}\end{array}$ & $\begin{array}{c}\text { F oran1 }(\%) \\
100 .(\mathrm{L} / \mathrm{W})\end{array}$ & Referans \\
\hline $\begin{array}{l}\text { Muz yalancı } \\
\text { gövde atiğ } 1\end{array}$ & 118.21 & 74 & 12.83 & 0.34 & 44.73 & 92.15 & Tespit \\
\hline Buğday sap1 & 56.06 & 30 & 34.77 & 2.28 & 90.72 & 16.12 & Deniz v, 2004* \\
\hline Pirinç sap1 & 60.13 & 43 & 28.38 & 1.36 & 81.30 & 21.19 & Tutuş vd., 2004* \\
\hline Çavdar sapı & 78.23 & 28 & 35.71 & 2.5 & 91.84 & 21.90 & Usta ve Eroğlu, 1987* \\
\hline Misır sap1 & 54.32 & 44 & 27.98 & 1.27 & 80.61 & 19.41 & Usta vd., 1990* \\
\hline Pamuk sapı & 32.42 & 67 & 16.49 & 0.49 & 55.04 & 19.66 & Tutuş vd., 2010* \\
\hline Kenaf & 58.37 & 57 & 19.46 & 0.74 & 66.98 & 30.00 & Ververis vd., 2004* \\
\hline Göl Kamışı & 102.96 & 52 & 24.07 & 0.92 & 73.11 & 32.32 & Kirc1, 1996* \\
\hline Bagas & 75.21 & 46 & 26.90 & 1.16 & 78.66 & 28.14 & Mather ve Wardman, 2010* \\
\hline Abaka & 144.39 & 84 & 7.76 & 0.18 & 28.63 & 186.11 & Moreno vd., 2005* \\
\hline Bambu & 152.32 & 46 & 27.15 & 1.18 & 79.12 & 56.10 & Deniz ve Ateş, 2002* \\
\hline Kivi & 44.03 & 62 & 19.00 & 0.61 & 61.58 & 231.56 & Yaman ve Gençer, 2005 \\
\hline IYYA & $60-80$ & $55-75$ & $13-20$ & $0.3-0.8$ & $50-60$ & $400-580$ & Tutuş vd.,2015 \\
\hline YA & $40-55$ & $35-55$ & $15-35$ & $0.5-1.8$ & $55-90$ & $150-300$ & Tutuș vd.,2015 \\
\hline
\end{tabular}

L: Lif uzunluğu (mm); D: Lif genişliği $(\mu \mathrm{m})$; d: Lümen çapı $(\mu \mathrm{m})$; W: Lif çeper kalınlığı $(\mu \mathrm{m}),{ }^{*} \mathrm{~L}, \mathrm{D}$, d and W değerleri referanslardan alınmış, diğer değerler hesaplanmıştır. IYA: İğne Yapraklı Ağaç, YA. Yapraklı Ağaç

Temel lif uzunlukları ile kağıt özellikleri arasında bir ilișki aramaktan ziyade bu verileri kullanarak türetilen keçeleşme oranı, elastiklik oranı, rijidite katsayısı ve runkel oranı ile lif kalitesini değerlendirmek, liflerin kağıt hamuru ve kağıt üretimine uygunluğunu belirlemek ve kağıt özelliklerini değerlendirmek daha doğru olacaktır (Saikia vd., 1997; Ogbonnaya vd., 1997; Kırc1, 2000).

Önceleri lif uzunluğunun kağıt özelliklerini etkileyen en önemli faktör olduğu düşünülmüş ancak yapılan çalışmalar lif uzunluğunun lif genişliğine oranı olan keçeleşme oranının çok daha önemli faktör olduğu tespit edilmiştir (Panshin ve Zeeuw, 1970; Tutuş vd., 2014). Keçeleşme oranı kağıdın fiziksel sağlamlık özelliklerinden yırtılma, patlama, kopma ve çift katlama dirençleri hakkında fikir veren önemli bir faktördür (Göksel, 1986; Bostanc1, 1987; Akgül ve Tozluoğlu, 2009). Keçeleşme oranı arttıkça yırtılma direnci de artar (Rydholm, 1965). Çizelge 3 incelendiğinde keçeleşme oranı bakımından muz yalancı gövde atığ liflerinin abaka ve bambu lifleri haricinde IYYA ve YA odun lifleri dahil çizelgedeki tüm diğer hammadde türlerinin liflerine ait keçeleşme oranından daha yüksek değere sahip olduğu görülmektedir. Bu şekilde keçeleşme oranı yüksek olan muz yalancı gövde atığı liflerinden üretilen kağıtların direnç özelliklerinin de yüksek olacağı tahmin edilmektedir. Ancak, kağıt ve kağıt hamuru üretiminde uzun liflerin tek başına kullanılması ile kağıt safihası oluşumunda liflerin düzensiz dağılması, topaklanma ve formasyonunda sorun oluşabilmektedir (Bostanc1, 1987; Kirc1, 2006).

Lümen çapının lif genişliğine oranlanması ile hesaplanan elastiklik katsayısı liflerin bağ yapma derecesini belirleyen önemli parametrelerden biridir (Smook, 1997). Kağıdın direnç özelliklerinden çekme direnci ile arasında pozitif ilişki bulunan elastikiyet katsayısının artışı ile çekme direnci de artmaktadır (Kırc1, 2000). Lifler, elastiklik katsayılarına göre dört gruba ayrılmıştır. Elastiklik katsayısı; 75 'ten daha büyük olan lifler çok esnek, 50-75 arası olan lifler elastik, 50-30 arası olan lifler sert ve 30'dan düşük olan lifler ise çok sert olarak sınıflandırılmıştır (Bektaş vd., 1999; Kırcı, 2000). Çizelge 3 irdelendiğinde 74 elastiklik değeri ile muz yalancı gövde atı̆g liflerinin yapılan esnek lifler grubunda olup çok esnek grubuna da oldukça yakındır. Bu değer IYA'da 55-75 ve YA'da 35-55 aralığındadır. İnce çeperli ve geniş lümenli muz yalancı gövde atığı lifleri kağıt üretimi sırasında çok iyi yassılaşma özelliği göstererek güçlü lif-lif bağlanması ile verimi yüksek kağıtların üretilebileceğini göstermektedir. Daha önce yapılan çalışmalar, elastiklik değeri yüksek (tercihen 60'dan yüksek) liflerin kağıt üretimi için önemini belirtmiştir (Petri, 1952; Okereke, 1962; Rydholm, 1965). Bu sonuca göre muz yalancı gövde atığı liflerinin kağıt hamuru ve kağıt üretimine uygun olduğu söylenebilmektedir. 
Runkel oranı lifin kağıt üretimi için uygunluğunu ve üretilen kağıdın kalitesini belirleyen bir değerdir (Ververis vd., 2004; David-Sarogoro ve Emerhi, 2016). Runkel oranı 1 'e eşit veya 1 'den küçük olan lifler hamurlaştırma işlemine uygun, 1'den büyük olan lifler ise hamurlaştırma işlemine uygun olmayan lifler olarak siniflandirılır (Kırc1, 2006). Okereke (1962) ve Rydholm (1965)'a göre, en iyi kağıt sağlamlık özellikleri için Runkel oranı 1'in altında olmalıdır (Ogbonnaya vd., 1997). Bu sayede lifler presleme sırasında çökerek kolayca yassılaşmakta, lifler arası bağlantı için geniş yüzey alanları oluşmakta ve daha sağlam lif-lif bağları oluşmaktadır (Dutt vd., 2004; Ezeibekwe vd., 2009). Çizelge 3 irdelendiğinde muz yalancı gövde atığının 0.34 Runkel oranı ile kağıt hamuru ve kağıt üretimi için oldukça uygun bir hammadde olduğu görülmektedir. Bu değer IYA (0.3-0.8) ve YA (0.5-1.8) değerlerine oldukça yakındır. Odun dışı hammaddeler arasından abakadan sonra en düșük Runkel oranına sahip olan muz yalancı gövde atığı kağıt hamuru ve kağıt üretimine en uygun liflere sahip olduğu tespit edilmiştir.

Rijidite katsayısının büyük olması kâğıdın kopma, yırtılma, patlama ve çift katlama dirençlerini olumsuz yönde etkiler (Huş vd., 1975). Çizelge 3'den görüldüğü üzere bu değer muz yalancı gövde atığında 12.83'dür. Karşılaştırma yapıldığında bu değer IYYA (13-20) ve YA (15-35)'dan ve abaka hariç diğer tüm yıllık bitki saplarından daha düşük olduğu görülmektedir.

Mühlstep oranı liflerin farklı şekilleri ve hücre duvarının kağıdın fiziksel özellikleri üzerindeki etkisi hakkında ön bilgi vermektedir. İnce çeperli lifler kağıt üretiminde kolaylıkla ezilir, bu da hem kağıt yoğunluğunu hem de direnç değerlerini olumlu yönde etkiler (Casey, 1960). Mühlstep oranı 30'dan düşük olan lifler şerit şeklindedir. İnce çeperli ve geniş lümenli olup keçeleşme özellikleri iyidir ve kağıt üretimine en uygun olan liflerdir. Mühlstep oranı 81'den yüksek orana sahip lifler ise kalın duvarlı ve küçük lümenli çubuk şeklinde lifler olup kağıt üretimine daha az kullanılabilir olan liflerdir. Mühlstep oranı 31-80 arasında olan lifler ise ara formlara sahip silindirik liflerdir (Simionescu vd., 1964). Kağıt üretiminde Mühlstep oranının düşük olması istenilmektedir. Muz yalancı gövde atığ1 liflerinin 44.73'lük Mühlstep oranı ile ara formlara sahip lifler olduğu ve kağıtçıllk için uygun olduğu söylenebilir. Muz yalanc1 gövde atığı liflerinin 50 ile 60 arasında Mühlstep oranına sahip IYYA lifleri ve 55 ile 90 Mühlstep oranına sahip YA liflerinden, IYA liflerine daha yakın olduğu görülmektedir. Çizelge 3'deki diğer tüm türlerin liflerinden (abaka hariç) daha düşük Mühlstep oranına sahip olduğu da görülmektedir.

Lif uzunluğunun lif çeper kalınlığına oranı şeklinde hesaplanan F oranı lif esnekliğinin ölçüsünü ifade eder ve kağıdın patlama, kopma direnci direnç özelliklerini etkiler (Horn, 1971; Horn ve Setterholm, 1990; Tutus vd., 2010). Yüksek F oranına sahip liflerden üretilen kağıtların elastikiyetleri de iyi olacaktır (Bostanc1, 1987). Çizelge 3'e göre muz yalancı gövde atığı liflerinin F oranı 92.15 olup bu değerin IYA odun liflerinin sahip olduğu 400-580 değer aralığının çok altında olduğu, YA odun liflerinin sahip olduğu 150-300 değer aralığına ise biraz daha yakın olduğu görülmüştür. Muz yalancı gövde atığının F değeri Çizelge 3 'deki abaka hariç diğer yıllık bitkilerin F oranı değerlerinin üzerinde olduğu, esnek liflere sahip olduğu söylenebilir.

\section{Sonuc}

Muz yalancı gövde atığının hammadde olarak kağıt hamuru ve kağıt üretimine uygunluğunun tespiti için kimyasal ve morfolojik özellikleri açısından değerlendirilmesi yapılmıştır. Kimyasal analizler sonucunda; muz yalancı gövde atığının holoselüloz içeriği açısından oldukça zengin olduğu, YA odunlarına yakın özellik gösterdiği, birçok yıllık bitki saplarına oranla daha yüksek $\alpha$-selüloz içeriğine sahip olduğu, IYYA ve YA odunlarına ve çoğu yıllık bitki saplarına oranla oldukça düşük oranda lignin içeriğine sahip olduğu tespit edilmiştir. Kül içeriği bakımından İYA ve YA odunlarına göre daha yüksek kül içeriğine sahip olmuş olsa da bu bakımından birçok yıllık bitkiye yakın özellik göstermiş ancak oldukça düşük oranda silis içeriğine sahip olduğu tespit edilmiştir. Kimyasal analizler sonucunda, yüksek holoselüloz ve $\alpha$ selüloz içeriği ile düşük lignin içeriği bakımından muz yalanc1 gövde atığı kağıt hamuru ve kağıt üretimi için oldukça uygun ve değerli bir hammaddedir. Çözünürlük değerleri bakımından çoğu tarımsal yıllık bitki saplarına benzer özellik gösterse de YA ve IYYA odunlarına kıyasla, düşük hamur verimine neden olabilecek yüksek çözünürlük içeriğine sahiptir. $\mathrm{Bu}$ durum, ileride yapılabilecek kağıt hamuru çalışmaları ile netleştirilebilir. Lif boyutları ve morfolojik indeksler bakımından değerlendirildiğinde, lif uzunluğu açısından İYA odun liflerine, lif genişliği açısından YA odun liflerine benzeyen muz yalancı gövde atı̆̆ lifleri, yüksek keçeleşme oranı ve elastikiyet katsayısı, düşük Runkel oranı, rijidite katsayısı ve Mühlstep oranı ve çoğu yıllık bitki saplarından yüksek, YA odun liflerine yakın F-oranı ile kağıt hamuru ve kağıt üretimine uygun bir hammaddedir.

\section{Açıklama}

Çalışmada hammadde teminini sağlayan Prof. Dr. Sedat ONDARAL'a, bazı analizlerin yapım aşamasındaki katkılarından dolayı Prof. Dr. Hüseyin KIRCI'ya ve Lif ve Kağıt Teknolojisi anabilim dalı laboratuvar imkanlarını sağlamalarından dolayı KTÜ Orman Fakültesi Orman Endüstri Mühendisliği bölümüne teşekkür ederiz.

\section{Kaynaklar}

Akgül, M., Tozluoglu, A., 2009. Some chemical and morphological properties of juvenile woods from beech (Fagus orientalis L.) and pine (Pinus nigra A.) plantations. Trends in Applied Sciences Research, 4(2): 116-125. doi: 10.3923/tasr.2009.116.125.

Akgül, M., Güler, C., Cöpür, Y., 2010. Certain physical and mechanical properties of medium density fiber boards manufactured from blends of corn (Zea mays indurate Sturt.) stalks and pine (Pinus nigra) wood. Turkish Journal of Agriculture and Forestry, 34(3): 197-206. doi: 10.3906/tar0902-26.

Ashori, A., Hamzeh, Y., Amani, F., 2011. Lemon balm (Melissa officinalis) stalk: Chemical composition and fiber morphology. Journal of Polymers and the Environment, 19(1): 297-300, 19:297-300. doi: 10.1007/s10924-010-0279-8.

Atchison, J.E., 1987. Data on non-wood plant fibers. In: The Secondary Fibers and Non-Wood Pulping: Third edition (Ed: Hamilton, F.), TAPPI Press, Atlanta, USA

Atchison, J.E., 1993. Data on non-wood plant fibers. In: Pulp and Paper Manufacture: Secondary Fibers and Nonwood Pulping (Ed: Kocurek, M.J.), TAPPI Press, Atlanta, vol 3, pp. 4-13. 
Bande M.M., Grenz, J., Asio, V.B., Sauerborn, J., 2013. Fiber yield and quality of abaca (Musa textilis var. Laylay) grown under different shade conditions, water and nutrient management. Industrial Crops and Products, 42: 70-77. doi: 10.1016/j.indcrop.2012.05.009.

Bektas, I., Tutus, A., Eroglu, H., 1999. A study of the suitability of Calabrian pine (Pinus brutiaten) for pulp and paper manufacture. Turkish Journal of Agriculture and Forestry, 23: 589-599.

Bostanc1, Ş., 1987. Kağıt Hamuru Üretimi ve Ağartma Teknolojisi, Karadeniz Teknik Üniversitesi Orman Fakültesi Yayınları, No:114/13. Trabzon.

Bozkurt, A.Y., Erdin, N., 1989. Odunsu lifler ve tanımı. İstanbul Üniversitesi Orman Fakültesi Dergisi, Seri B, 39(4):1-16.

Casey, J.P., 1960. Pulp and Paper Chemistry and Chemical Technology Vol.1, Wiley Interscience Publisher Inc., New York.

David-Sarogoro, N., Emerhi, E.A., 2016. Runkel, flexibility and slenderness ratios of Anthocleista djalonensis (A) wood for pulp and paper production. African Journal of Agriculture, Technology and Environment, 5(2): 27-32.

Demirel, B., P1nar, H., 2019. Determination of possible energy potential of banana residues in Turkey. Turkish Journal of Agriculture - Food Science and Technology, 7: 41-45. doi: 10.24925/turjaf.v7isp2.41-45.3117.

Deniz, I., Ates, S., 2002. Determination of optimum kraft pulping conditions using bamboo (Pyllotachys bambusoides). 2nd National Black Sea Forestry Congress Proceedings, 15-18 May, Artvin, Turkey, pp. 1072- 1084.

Deniz, I., Kırc1, H., Ates, S., 2004. Optimization of wheat straw (Triticum drum) kraft pulping, Industrial Crops and Products, 19(3): 237-243. doi: 10.1016/j.indcrop.2003.10.011.

Dutt, D., 1994. Pulping studies on Cannabis sativa and Ipomea carnea. PhD Dissertation, University of Roorkee, India.

Dutt, D., Upadhyaya, J.S., Malik, R.S., Tyagi, C.H., 2004. Studies on pulp and papermaking characteristics of some Indian nonwoody fibrous raw materials: Part-II. Journal of Scientific and Industrial Research, 63(2): 58-67.

Eroğlu, H. 1980. $\mathrm{O}_{2}-\mathrm{NaOH}$ Yöntemiyle buğday (Triticum aestivum L.) saplarından kağıt hamuru elde etme olanaklarının araştırılması, Doçentlik Tezi, KTÜ Orman Fakültesi, Trabzon.

Eroğlu, H., Usta, M., Kırc1, H., 1992. A review of oxygen pulping conditions of some non-wood plant growing in Turkey. Tappi Pulping Conference, 1-5 November, Boston, USA, pp. 215-22.

Eroğlu, H., 2003. Kağıt Hamuru ve Kağıt Fiziği Ders Notları. Zonguldak Karaelmas Üniversitesi, Bartın Orman Fakültesi Yayınları, Yayın No:27, Fakülte Yayın No:13, Bartın.

Ezeibekwe, I.O., Okeke, S. E., Unamba, C.I., Ohaeri, J.C., 2009. An investigation into the potentials of Dactyladenia bacteri, Dialum guineense and Anthonota macrophylia for paper pulp production. Report and Opinion, 1(4): 18-25. doi: 10.7537/marsroj010409.04.

Franklin, G.L., 1945. Preparation of thin sections of synthetic resins and wood resin composites and a new maceration method for wood. Nature, 155(3924): 51-51.

Gençer, A., 2015. The utilization of Kiwi (Actinidia deliciosa) pruning waste for kraft paper production and the effect of the bark on paper properties. Drewno, 58(194): 103-113. doi: 10.12841/wood.1644-3985.084.08.

Goyal, S.K., Ray, A.K., 1989. Economic comparison of soda and soda-AQ pulping processes for cereal straws, Tappi Pulping Conference, 22-25 October, Seattle, pp. 775-780.

Göksel, E., 1986. Pamuk saplarının selüloz ve kağıt endüstrisinde kullanım olanakları üzerine araştırmalar, İstanbul Üniversitesi Orman Fakültesi Dergisi, Seri A, 36(1): 38-54.

Gumuskaya E., Usta, M., 2006. Dependence of chemical and crystalline structure of alkali sulfite pulp on cooking temperature and time. Carbohydrate polymers, 65(4): 461-468. doi: 10.1016/j.carbpol.2006.02.004.
Horn, R.A., 1971. Fiber morphology considerations in paper properties. Symposium on Effect of Growth Acceleration on the Properties of Wood, pp. B1-B11., November 10-11, Madison, USA.

Horn, R.A., Setterholm V.C., 1990. Fiber morphology and new crops. In: Advances in New Crops (Ed: Janick, J., Simon J. E.), Timber Press, Portland, pp. 270-275.

Hurter, R.W., 1997. Nonwood plant fiber characteristics. Agricultural Residues, 1: 1-4.

Hussain, I., Tarar, O.M., 2014. Pulp and paper making by using waste banana stem. Journal of Modern Science and Technology, 2(2): 36-40.

Huş, S., Tank, T., Göksal, E., 1975. Considering eucalytus (E. camaldulensis Dehnh.) wood which grow in Turkey (in TarsusKarabacak) morphologically and opportunities for evaluating semi chemical cellulose in paper industry, Tubitak Publications, USA.

Ilvessalo-Pfäffli, M.S.,1995. Fiber Atlas: Identification of papermaking fibers. Springer-Verlag, Berlin.

Kalyoncu, E.E., 2011. Buğday saplarından (Triticum aestivum) çeşitli yöntemlerle elde edilen hamurların ağartılma karakteristiklerinin belirlenmesi, Doktora tezi, Karadeniz Teknik Üniversitesi, Fen Bilimleri Enstitüsü, Trabzon.

Kara, E.E., Sezer, İ., 1992. Anız Yakma. Ekoloji, 2(5): 18-22.

Khan, M.Z., Sarkar, M.A., Forhad, I.A., Khan, M.Z., Raimo, O.M., 2014. Paper making from banana pseudo-stem: Characterization and comparison. Journal of Natural Fibers, 11: 199-211. doi: 10.1080/15440478.2013.874962.

Khristova, P., Gabir, S., Bentcheva, S., Dafalla, S., 1998. Sodaanthraquinone pulping of sunflower stalks. Industrial Crops and Products, 9(1): 9-17. doi: 10.1016/S0926-6690(98)000089.

Kırcı, H., 1996. Soda-oksijen yöntemi ile göl kamışından (Phragmites communis L.) kağıt hamuru üretim koşullarının belirlenmesi, Karadeniz Teknik Üniversitesi Araştırma Fonu, No. 95.113.002.6, Trabzon.

Kırcı, H., 2000. Kağıt Hamuru Endüstrisi Ders Notları. Karadeniz Teknik Üniversitesi Orman Fakültesi Yayınları, Yayın No:63, Trabzon.

Kırcı, H., 2006. Kağıt Hamuru Endüstrisi Ders Notları. Karadeniz Teknik Üniversitesi Orman Fakültesi Yayınları, Yayın No:86, Trabzon.

Kumar, M., Kumar, D., 2011. Comparative study of pulping of banana stem. International Journal of Fibre and Textile Research, 1(1): 1-5.

Li, K., Fu, S., Zhan, H., Zhan, Y., Lucia, L., 2010. Analysis of the chemical composition and morphological structure of banana pseudo-stem. BioResources, 5: 576-585.

Mather, R.R., Wardman, R.H., 2010. The Chemistry of Textile Fibres. Royal Society of Chemistry Publishing, Cambridge.

Moreno, L.O., Parac, A.A., Ocon, F.L., 2005. Fiber characteristics of promising abaca (Musa textilis Nee) accessions in NARC (National Abaca Research Center) germplasm suited for specific industry end uses. Philippine Journal of Crop Science, 30(1): 60 .

Nicemol, J., Niladevi, K.N., Anisha, G.S., Prema, P., 2007. Pineapple \& banana fibre. Asian Textile Journal, 1: 38-44.

Nieschlag, H.J., Nelson, G.H., Wolff, J.A., Perdue, R.E., 1960. A search for new fibre crops. TAPPI Journal, 43(3): 193-201.

Ogbonnaya, C.I., Roy-Macauley, H., Nwalozie, M.C., Annerose, D.J.M., 1997. Physical and histochemical properties of kenaf (Hibiscus cannabinus L.) grown under water deficit on a sandy soil. Industrial Crops and Production, 7: 9-18. doi: 10.1016/S0926-6690(97)00034-4.

Okereke, O.O., 1962. Studies on the fibre dimensions of some Nigerian timbers and raw materials. Part 1. Res. Rep. No.16., Fed. Ministry of Commerce and Industry, Lagos, Nigeria.

Oluwasina, O.O., Lajide, L., 2016. Evaluation of compositional properties of some plant wastes for industrial applications. FUTA Journal of Research in Sciences, 12(2): 180-187. 
Omotoso, M.A., Ogunsile, B.O., 2009. Fibre and chemical properties of some Nigerian grown Musa species for pulp production. Asian Journal of Materials Science, 1(1): 14-21. doi: 10.3923/ajmskr.2009.14.21

Ortega, Z., Morón, M., Monzón, M.D., Badalló, P., Paz, R., 2016. Production of banana fiber yarns for technical textile reinforced composites. Materials, 9(5): 370. doi: 10.3390/ma9050370.

Padam, B.S., Tin, H.S., Chye, F.Y., Abdullah, M.I., 2014. Banana by-products: An under-utilized renewable food biomass with great potential. Journal of Food Science and Technology, 51(12): 3527-3545. doi: 10.1007/s1319 7-012-0861-2.

Panshin, A.J., Zeeuw, C., 1970. Textbook of Wood Technology. M.C. Graw-Hill Book Company, London.

Petri, R., 1952. Pulping studies with African tropical woods. TAPPI, 35: 157-160.

Poonam, B., Gupta, K.C., 1991. Physio-chemical properties of banana fibre. Indian Textile Journal, 2: 60-62.

Pothan, L.A., George, C.N., John, M.J., Thomas, S., 2010. Dynamic mechanical and dielectric behavior of banana-glass hybrid fiber reinforced polyester composites. Journal of Reinforced Plastics and Composites, 29(8): 1131-1145. doi: 10.1177/0731684409103075.

Rahman, M.M., Islam, T., Nayeem, J., Jahan, M.S., 2014. Variation of chemical and morphological properties of different parts of banana plant (Musa paradisica) and their effects on pulping. International Journal of Lignocellulosic Products, 1(2): 93-103. doi: 10.22069/IJLP.2014.2065.

Ramesh, M., Atreya, T.S.A., Aswin, U.S., Eashwar, H., Deepa, C., 2014. Processing and mechanical property evaluation of banana fiber reinforced polymer composites. Procedia Engineering, 97: 563-572. doi: 10.1016/j.proeng.2014.12.284.

Reddy, N., Yang, Y., 2015. Fibers from banana pseudo-stems. In: Innovative Biofibers from Renewable Resources. (Ed: Reddy, N., Yang, Y.), Springer, Berlin, pp. 25-27.

Redondo-Gómez, C., Rodríguez Quesada, M., Vallejo Astúa, S., Murillo Zamora, P.Z., Lopretti, M., Vega-Baudrit, J.R., 2020. Biorefinery of biomass of agro-industrial banana waste to obtain high-value biopolymers. Molecules, 25(17): 3829, doi: 10.3390/molecules25173829.

Rydholm, S.A., 1965. Pulping processes. Interscience Publishers, New York.

Saikia, S.N., Goswami, T., Ali, F., 1997. Evaluation of pulp and paper making characteristics of certain fast growing plants. Wood Science and Technology, 31: 467-475.

Shakhes, J., Marandi, M.A.B., Zeinaly, F., Saraian, A., Saghafi, T., 2011. Tobacco residuals as promosing lignocellulosic materials for pulp and paper industry. BioResources, 6: 4481-4493.

Sharma, A.K., Dutt, D., Upadhyaya, J.S., Roy, T.K., 2011. Anatomical, morphological, and chemical characterization of Bambusa tulda, Dendrocalamus hamiltonii, Bambusa balcooa, Malocana baccifera, Bambusa arundinacea and Eucalyptus tereticornis. BioResources, 6: 5062-5073. doi: 10. 15376/biores.6.4.5062-5073.

Simionescu, C.I.M., Grigora, S., Cernatescu-Asandei, A., 1964. Chemistry of Wood in R.P.R. Bucharest. Academy of Popular Republic of Romania Publishing House.

Singh, H.R., Uma, S., Selvarajan, R., Karihaloo, J.L., 2011. Micropropagation for production of quality banana plamting material in Asia-pacific. In: Asia-pasific consortium on Agricultural Biotechnology (APCoAB), New Delhi, India, pp. 92.

Singh, L., Bandyopadhyay, T.K., 2013. Handmade paper from banana stem. International Journal of Scientific and Engineering, 4(7): 2074-2079.

Smook, G.A., 1997. Handbook for Pulp and Paper Technologists. Angus Wilde Publications, Vancouver.

Soffner, M.L.A.P., 2001. Pulp production from banana stem. Master Thesis, University of Sao Paulo, Brazil.
Sun, R.C., Tomkinson, J., 2003. Comparative study of organic solvent and water-soluble lipophilic extractives from wheat straw I: Yield and chemical composition. Journal of Wood Science, 49(1): 47-52.

Tank, T., Bostancı, Ş., Eroğlu, H., Enercan, S., 1985. Tütün saplarının kağıt yapımında değerlendirilmesi. Doğa Bilim Dergisi, D2, 9: 3.

TAPPI T $203 \mathrm{~cm}-09,2009$. Alpha-beta and gamma cellulose in pulp. Tappi Press, Atlanta, GA, USA.

TAPPI T $204 \mathrm{~cm}-17,2017$. Solvent extractives of wood and pulp. Tappi Press, Atlanta, GA, USA

TAPPI T 222 om-15, 2015. Acid-insoluble lignin in wood and pulp. Tappi Press, Atlanta, GA, USA.

TAPPI T 211 om-16, 2016. Ash in wood, pulp, paper and paperboard: Combustion at $525^{\circ} \mathrm{C}$. Tappi Press, Atlanta, GA, USA.

TAPPI T $245 \mathrm{~cm}-07,2007$. Silicates and silica in pulp (Wet Ash Method). Tappi Press, Atlanta, GA, USA.

TAPPI T 207 om-08, 2008. Water solubility of wood and pulp. Atlanta, GA, USA.

TAPPI T 212 om-12, 2012. One percent sodium hydroxide solubility of wood and pulp. Tappi Press, Atlanta, GA, USA

TAPPI T 257 sp-14, 2014. Preparation of wood for chemical analysis. Tappi Press, Atlanta, GA, USA.

TUIK, 2021. Bitkisel Üretim İstatistikleri 2020, Tablo-3 Meyve ürünleri, içecek ve baharat bitkileri üretim miktarları, https://data.tuik.gov.tr/Bulten/Index?p=Bitkisel-UretimIstatistikleri-2020-33737, Erişim: 07.06.2021

Tutuş, A., Deniz, İ., Eroğlu, H., 2004. Rice straw pulping with oxide added soda-oxygen-antraquinone. Pakistan Journal of Biological Sciences, 7(8):1350-1354. doi 10.3923/pjbs.2004.1350.1354.

Tutus, A, Ezici, A.C., Ates, S., 2010. Chemical, morphological and anatomical properties and evaluation of cotton stalks (Gossypium hirsutum L.) in pulp industry. Scientific Research and Essays, 5(12): 1553-1560. doi: 10.5897/SRE.9000265.

Tutuş, A., Çiçekler, M., Özdemir, F., Yılmaz, U., 2014. Kahramanmaraş koşullarında yetişen Trabzon hurma ağacı (Diospyros kaki)'nın kağıt hamuru ve kağıt üretiminde değerlendirilmesi. II. Ulusal Akdeniz Orman ve Çevre Sempozyumu, 22-24 Ekim, Isparta, s.775-784.

Tutus, A., Cicekler, M., 2016. Evaluation of common wheat stubbles (Triticum aestivum L.) for pulp and paper production. Drvna Industrija, 67(3): 271-279. doi: 10.5552/drind.2016.1603.

Tutuș, A., Kazaskeroğlu, Y., Ciçekler, M., 2015. Evaluation of tea wastes in usage pulp and paper production. BioResources, 10(3): 5407-5416.

Usta, M., Eroğlu, H., 1987. Soda-oxygen pulping of rye straw. In: Nonwood Plant Fiber Pulping Conference Progress Report No:18, Tappi Press, Washington, pp. 113-118.

Usta, M., Kırc1, H., Eroglu, H., 1990. Soda-oxygen pulping of corn (Zea mays indurata sturt). Tappi Pulping Conference, October 14-17, Toronto, Ontario, Canada, pp. 307-312.

Ververis, C., Georghiou, K., Christodoulakis, N., Santas, P., Santas, R., 2004. Fiber dimensions, lignin and cellulose content of various plant materials and their suitability for paper production. Industrial Crops and Products, 19: 245-254. doi:10.1016/j.indcrop.2003.10.006.

Wilcox, W.W., Piirto, D.D., 1976. Decay resistance in redwood (Sequoia sempervirens) heartwood as related to color and extractives. Wood Fiber Science, 7(4): 240-245.

Wise. E.L., Karl, H.L., 1962. Cellulose and hemicelluloses in pulp and paper science and technology, Vol. 1. Pulp (Ed: C. Earl Libby), McGraw Hill-Book Co., New York.

Yaman, B., Gençer, A., 2005. Trabzon koşullarında yetiştirilen kivi (Actinidia deliciosa (A. Chev.) C.F. Liang \& A.R Ferguson)'nin lif morfolojisi. Süleyman Demirel Üniversitesi Orman Fakültesi Dergisi, Seri: A, 2:149-155. 